\title{
An overview of the benefits of peer mentoring for PASS leaders
}

\section{Melanie Giles}

Ulster University, UK

Amanda Zacharopoulou

Ulster University, UK

\section{Joan Condell}

Ulster University, UK

\begin{abstract}
PASS, which stands for Peer Assisted Study Sessions, is a long running and internationally renowned form of peer learning that involves trained higher year students (PASS leaders) working in pairs to facilitate regular study groups with students in the year below. Not only does it aim to widen participation by providing a support mechanism aimed at helping students stay in Higher Education but the use of PASS has been shown to enhance academic performance and promote the development of skills and attributes to strengthen employability. This is particularly the case for PASS leaders who are often described as the 'real winners' in the process. However, research in this area is limited. With this in mind, this paper sets out to describe the particular benefits of PASS for peer leaders and, in so doing, draws on some peer mentoring research, much of which has been conducted in an American and Australian context. As such, the paper should be of particular interest to those wishing to determine whether the various claims can be generalised to the PASS process, as it currently exists within the UK.
\end{abstract}

Keywords: PASS; peer mentoring; benefits; employability skills. 


\section{Introduction}

Since its inception within the UK, there has been a proliferation of PASS/PAL (Peer Assisted Learning) activity within many degree programs and research evidence is available to suggest that the scheme has the potential to: enhance academic performance (Bidgood, 1994; McCarthy et al., 1997; Coe et al., 1999; Ashwin, 2003; Rodger and Tremblay, 2003); aid the transition process (Glaser et al., 2006; Giles et al., 2012; Collings et al., 2015) and reduce student drop-out (Higgins, 2004; Bolton et al., 2009; Collings et al., 2014; Pugliese et al., 2015). Whilst the quasi-experimental comparison of grades between those who attend sessions and those who don't has led to some criticism of these findings, with the suggestion that there may be a degree of self-selection involved (Capstick, 2004), more rigorous longitudinal studies conducted within the US have reinforced the notion that academic achievement is enhanced (e.g. Loviscek and Cloutier, 1997). There is also some evidence to suggest that the scheme serves to engender enthusiasm for the discipline; provide an additional mechanism for communication and feedback between teaching staff and students; increase group cohesiveness; enhance employability and more generally enhance the quality of the student learning experience (see Capstick and Fleming, 2001; Capstick, 2004; Laurs, 2009).

More recently, various commentators have begun to acknowledge that PASS participants are not the only ones to benefit from the peer mentoring process (Stout and McDaniel, 2006; Skalicky, 2008). For example, Donelan (1999) described student leaders as 'the real winners' believing them to acquire a range of transferable skills and experiences (see also, Drew et al., 2000; Heirdsfield et al., 2008; Smith, 2008; Terrion and Philion, 2008; Bolton, et al., 2009; Bunting et al., 2012). These skills are generally reported as employability skills or lists of graduate attributes (Skalicky and Caney, 2010), with many writers choosing to categorise them in different ways. For example, Couchman (2009) reports on generic leadership skills, which may be said to include 'communication', 'organisational' and 'group skills', 'self-confidence' and 'teamwork'. Alternatively, Congos and Stout (2003) identify categories of benefits including 'learning', 'leadership', 'interpersonal relations' and 'work related' skills and 'content knowledge'. However, perhaps the ways in which leaders benefit could be more usefully described in terms of their academic, personal and professional development (Stout and McDaniel, 2006). 


\section{Academic benefits}

Whilst it is acknowledged that the academic benefits of being a PASS leader are generally secondary to the personal and professional outcomes more frequently reported leaders often comment that the process of having to familiarise themselves with course materials in preparing for sessions serves to increase their understanding of the subject matter (Ashwin, 1994; see also Calder, 2004; Shrestha et al., 2008):

As facilitators of learning, they must think through and mentally organise information before explaining it to students. This process forces peer leaders to engage with the material at a deep level, helping to solidify their own understanding of it. (Micari et al., 2005, p.270).

In a traditional PASS setting, leaders are encouraged to use the student's lecture notes to facilitate group discussion. However, technological advances, specifically the widespread availability of various teaching resources through the virtual learning environment, has reduced the need for students to take notes during lectures with the result that the structure this imposed on PASS sessions is now often missing. Whilst leaders are reassured that PASS is also based on the premise that the participants themselves set the agenda, they are often unwilling or ill-equipped to do so. This puts more emphasis on the leaders to identify relevant and purposeful activities of an appropriate level of difficulty to engage students during sessions (e.g. games and quizzes) which in turn serves to enhance their own learning and study habits (Donelan, 1999; Ogden et al., 2003; Stone et al., 2008).

\section{Personal benefits}

\section{Confidence}

Of course, as Stout and McDaniel (2006) acknowledge, as the leaders understanding of their course content is enhanced so too is their self-confidence. Indeed, confidence and self-esteem are probably the most frequently cited personal attributes to develop as a result of the PASS process (e.g. Wallace, 1992; Ashwin, 1994; Donelan, 1999; Stone et al., 2012). This is probably not surprising given the nature of tasks and/or activities leaders are required to perform and the associated attributes that develop as a consequence. For example, preparing materials in advance of sessions and dealing with students' issues and 
concerns during the sessions themselves are said to enhance their problem-solving and time-management skills. Not only do leaders have to plan their PASS activities in and around their own work schedules but they must attend weekly PASS and debrief classes, arrive on time and manage timings within each session including opening and closing the sessions appropriately. Allowing participants to set the agenda and having a contingency plan if they arrive with nothing and responding to their varying needs within each session will also serve to develop their flexibility and adaptability. As Stout and McDaniel (2006) acknowledge:

Session plans must be flexible enough to accommodate the needs of the students attending. (Stout and McDaniel, 2006, p. 57).

\section{Interpersonal relationships}

Responding to the various needs of students often from quite diverse backgrounds will also serve to develop leaders' skills in interpersonal relations (Laurs, 2009; Stone et al., 2012) and promote a better understanding of cultural diversity:

In collaborative endeavours, students inevitably encounter difference and must grapple with recognising and working with it. Building the capacities for tolerating or resolving differences, for building agreement that honours all the voices in a group, for caring how others are doing - these abilities are crucial aspects of living in a community. (Smith and MacGregor, 1992, p.3).

Leaders will also be encouraged to consider the different learning styles of their mentees and adapt activities accordingly. Their role is to establish a supportive environment so that all participants feel confident to ask questions, make mistakes and practice their subject in private. This will require a degree of emotional intelligence (Goleman, 1995). Indeed, to be effective, leaders must be attuned to the feelings of others and move them in a positive emotional direction. They must also be able to recognise when students are experiencing problems and be able to refer them to the appropriate sources of help if required. 


\section{Communication skills}

Interacting with participants during PASS sessions also serves to improve the leaders' communication skills (e.g. Muldoon, 2008; see also Beltman and Schaeben, 2012). Not only are they required to set appropriate boundaries but they must also be able to employ appropriate strategies to deal with difficult situations. Leaders will be introduced to communication theory during training and will frequently be required to use their skills to engage participants who are silent and unresponsive or who stop listening to each other and start to engage in private conversations. They will also be required to deal effectively with those who arrive late or become dominant and aggressive. They must also be able to assess the student's level of understanding in order to plan activities using both verbal and non-verbal cues (Ashwin, 1994). Obviously good listening and questioning skills will be fundamental to this process. As trained facilitators, they must be able to engage the group in exploratory discussion and redirect questions since their role is not to give answers but to inspire participants to identify their own solutions or possible sources of help. Being able to establish a rapport with their group will also be important in promoting attendance. In this respect, many leaders will use social networking sites (e.g. Facebook) to communicate with their group outside of sessions. Their ability to express themselves in written form may also be enhanced as they are frequently required to produce materials to facilitate learning. Moreover, delivering these materials and providing feedback on their progress during the weekly debriefs will serve to further develop their presentation skills.

\section{Teamwork}

As a consequence, most PASS leaders will have established effective study groups and will use the session strategies and group facilitation techniques acquired during training to further develop their team working skills (Donelan, 1999). Indeed, PASS sessions are designed to promote collaborative learning and as such, all activities employed by leaders will be designed to encourage participation at the group level. However, PASS is also a process that involves 'learning by doing' and as such there will be a focus on the development of creativity skills during training and associated events (e.g. annual PASS student conference) during which leaders are actively encouraged to think of novel ways to engage participants with their academic content. These skills will be further developed during the weekly debriefs which generally require the leaders to work in groups as they reflect on progress and plan for subsequent sessions. 


\section{Leadership}

Inherent within many of these activities is the concept of leadership. Leadership is a difficult concept to define and perhaps as a consequence many writers have chosen to express the benefits gained from being a PASS leader as generic 'leadership skills' which include many of the attributes already discussed (e.g. Couchman, 2009). Skalicky and Caney (2010), for example, report that the most common aspect of the PASS leadership role is 'organisation'. In the words of one of their students:

The preparation that goes in beforehand is part of leadership that most people don't consider, but it's just as integral as standing up in front of a group of students and talking about bonding. It's also setting a good example to the students: you can't just rock up and expect everything to work. (Skalicky and Caney, 2010, p. 29).

However, effective leadership is clearly more than being organised. Increasingly, it is being recognised that good leadership occurs when 'heart and head' meet 'feeling and thought'. In other words, effective leaders:

Execute a vision by motivating, guiding, inspiring, listening, persuading and creating resonance. (Goleman et al., 2002).

This is very much in keeping with affiliative leadership and suggests that the ability to empathise with others is fundamental to being a good leader. This focus on the emotional needs of others is very much at the heart of the PASS process and there is some evidence to suggest that PASS leaders experience growth in these skills as their role develops. Indeed, Skalicky and Caney (2010) identified twelve aspects of leadership developed in the role including a number of dimensions that are in keeping with a person-centered approach to leadership such as providing advice (support), guiding discussion (facilitation), working with others (collaboration) and creating an atmosphere (relationships).

\section{Professional benefits}

PASS leaders will also benefit professionally from the relationships they develop with each other, with the academic staff associated with the PASS process (see Martin and Wilcox, 1996; Eisen et al., 2014) and from the knowledge they acquire about their own university 
or institution (Drew et al., 2000; Ehrich et al., 2004; Bunting et al., 2012). Working in pairs, leaders are often required to lead sessions with other students they may not necessarily have chosen as friends. They will also be required to work closely with those academic staff teaching on modules affiliated with the PASS process which should further develop their communication skills and serve to foster mature and professional relationships. Leaders will also be trained to view the PASS process as confidential. Sessions are presented as 'a safe place to ask questions' and to explore issues that participants might not want to address in lectures. Leaders must respect this and summarise the outcomes of their sessions during the weekly debriefs in a confidential and professional manner. As part of this process, leaders are continually required to reflect critically on their role and personal experiences which is probably one of the most important aspects of their professional development and improvement (Ehrich et al., 2004; Gilles and Wilson, 2004; see also Heirdsfield et al., 2008). Reflective practice is certainly an effective tool in practice-based professional learning settings and in this context has been shown to impact on confidence and the quality of PASS sessions (Skalicky, 2008).

\section{Conclusion}

In spite of the above, it is important to acknowledge that much of what has been written about the PASS/PAL process is based on the American or Australian model or relates to peer mentoring research more generally. Much less has been written about the benefits to PASS leaders within a UK context. Some have alluded to the potential gains but generally not in any great depth and often not in any coordinated fashion. As Couchman (2009) acknowledges, the benefits to leaders have been noted in a variety of documents ranging from post-session forms, surveys, semi-structured interviews and discussion groups (Capstick, 2004) to weekly journals (Lundeberg and Moch, 1995), portfolios and narratives (Green, 2007). Moreover, the information reported is often secondary to the primary aim of exploring the benefits to PASS participants. Certainly, there is still 'a dearth of research on the skills leaders feel they gain' (Stout and McDaniel, 2006, p.61) and that which does exist is based almost exclusively on a qualitative perspective. Rarely have quantitative methods been employed other than to determine the impact on academic performance. Indeed, evaluative research is limited (see Gershenfeld, 2014; Collings et al., 2015). As such, more research is needed not only to determine whether the various claims can be 
generalised outside their specific contexts but perhaps more importantly, to ensure ongoing improvements in training and in programme design and delivery.

\section{References}

Ashwin, P. (1994) 'The supplemental instruction leader experience, why supplemental instruction is not teaching: a student's perspective', in Rust, C. R. and Wallace, J. (eds.) Helping students to learn from each other: supplemental instruction. Birmingham, UK: Staff and Educational Development Association, pp. 87-90.

Ashwin, P. (2003) 'Peer support: relations between the context, process and outcomes for students who are supported', Instructional Science, 31(3), pp. 159-173. DOI: http://www.doi.org/10.1023/A:1023227532029

Beltman, S. and Schaeben, M. (2012) 'Institution-wide peer mentoring: benefits for mentors'. The International Journal of the First Year in Higher Education, 3(2), pp. 33-44. DOI: http://dx.doi.org/10.5204/intjfyhe.v3i2.124

Bidgood, P. (1994) 'The success of supplemental instruction: statistical evidence', in Rust, C. R. and Wallace, J. (eds.) Helping students to learn from each other: supplemental instruction. Birmingham, UK: Staff and Educational Development Association, pp. 71-79.

Bolton, T., Pugliese, T., and Singleton-Jackson, J. (2009) 'Advancing the promotion of information literacy through peer-led learning', Communications in Information Literacy, 3(1), pp. 20-30.

Bunting, B., Dye, B., Pinnegar, S. and Robinson, K. (2012) 'Understanding the dynamics of peer mentor learning: a narrative study', Journal of The First-Year Experience and Students in Transition, 24(1), pp. 61-78.

Calder, A. (2004) 'Peer interaction in the transition process', Journal of the Australia and New Zealand Student Services Association, 23, pp. 4-16. 
Capstick, S. (2004) Benefits and shortcomings of peer assisted learning (PAL) in higher education: an appraisal by students', Peer Assisted Learning Conference. January 2004, Bournemouth University, UK. Available at:

https://www1.bournemouth.ac.uk/sites/default/files/asset/document/stuartcapstick.pdf (Accessed: 5 April 2016).

Capstick, S. and Fleming, H. (2001) 'Peer assisted learning in an undergraduate hospitality course: second year students supporting first year students in group learning', Journal of Hospitality, Leisure, Sport \& Tourism Education, 1(1), pp. 6975.

Coe, E., McDougall, A. and McKeown, N. (1999) 'Is peer assisted learning of benefit to undergraduate chemists?', University Chemistry Education, 3(2), pp. 72-75.

Collings, R., Swanson, V. and Watkins, R. (2014) 'The impact of peer mentoring on levels of student wellbeing, integration and retention: a controlled comparative evaluation of residential students in UK higher education', Higher Education - The International Journal of Higher Education Research, 68(6), pp. 927-942. DOI: http://dx.doi.org/10.1007/s10734-014-9752-y

Collings, R., Swanson, V. and Watkins, R. (2015) 'Peer mentoring during the transition to university: assessing the usage of a formal scheme within the UK', Studies in Higher Education, pp. 1 - 16. http://dx.doi.org/10.1080/03075079.2015.1007939

Congos, D. and Stout, B. (2003) 'The benefits of SI leadership after graduation', Research and Teaching in Developmental Education, 20(1), pp. 29-41.

Couchman, J. A. (2009) 'An exploration of the lived experience of one cohort of academic peer mentors at a small Australian university', Journal of Peer Learning, 2(1), pp. 87-110.

Donelan, M. (1999) 'SI leaders: the real winners', National Conference on Supplemental Instruction. University of Missouri, Kansas City, USA 20-22 May. 
Drew, N., Pike, L., Pooley, J., Young, A. and Breen, L. (2000) 'School of psychology peer mentoring pilot programme', The Fourth Pacific Rim - First Year in Higher Education Conference: Creating Futures for a New Millennium. Queensland University of Technology, Brisbane, Australia 5-7 July [Online]. Available at: http://www.fyhe.com.au/past papers/abstracts/PooleyAbstract.htm (Accessed: 13 April 2016).

Ehrich, L., Hansford, B. and Tennent, L. (2004) 'Formal mentoring programs in education and other professions: a review of the literature', Educational Administration Quarterly, 40(4), pp. 518-540. http://dx.doi.org/10.1177/0013161X04267118

Eisen, S., Sukhani, S., Brightwell, A., Stoneham, S. and Long, A. (2014) 'Peer mentoring: evaluation of a novel programme in paediatrics', Archives of Disease in Childhood, 99(2), pp. 142-146. http://dx.doi.org/10.1136/archdischild-2013-304277

Gershenfeld, S. (2014) 'A review of undergraduate mentoring programs', Review of Educational Research, 84(3), pp. 365-391. http://dx.doi.org/10.3102/0034654313520512

Giles, M., Zacharopoulou, A. and Condell, J. (2012) 'Peer assisted study sessions: the evaluation of a cross-faculty initiative in Ulster', Centre for Higher Education Practice - Perspectives on Pedagogy and Practice, 3, pp. 67-80.

Gilles, C. and Wilson, J. (2004) 'Receiving as well as giving: mentors' perceptions of their professional development in one teacher induction program', Mentoring and Tutoring: Partnership in Learning, 12(1), pp. 87-106. http://dx.doi.org/10.1080/1361126042000183020

Glaser, N., Hall, R. and Halperin, S. (2006) 'Students supporting students: the effects of peer mentoring on the experiences of first year university students', Journal of the Australia and New Zealand Student Services Association (JANZSSA), 27, pp. 4-17.

Goleman, D. (1995) Emotional intelligence: why it can matter more than IQ. New York: Bantam Books. 
Goleman, D., Boyatzis, R. and McKee, A. (2002) 'The emotional reality of teams', Journal of Organizational Excellence, 21(2), pp. 55-65. http://dx.doi.org/10.1002/npr.10020

Green, A. (2007) 'Peer Assisted Learning: empowering first year engagement with a formal curriculum through the educative'. Available at: https://www.exeter.ac.uk/media/universityofexeter/academicservices/changeagents/ pal/PAL research.pdf

Heirdsfield, A., Walker, S., Walsh, K. and Wilss, L. (2008) 'Peer mentoring for first- year teacher education students: the mentors' experience', Mentoring and Tutoring: Partnership in Learning, 16(2), pp. 109-124. http://dx.doi.org/10.1080/13611260801916135

Higgins, B. (2004) 'Relationship between retention and peer tutoring for at-risk students'. Journal of Nursing Education, 43(7), pp. 319-321. http://dx.doi.org/10.3928/01484834-20040701-01

Laurs, D. E (2009). Developing Student Leaders' graduate attributes: How student learning support can play a part. In M.A.F Silvester (Ed.) Transformations: Proceedings of the2008 Annual International Conference of the Association of Tertiary Learning Advisers of Aotearoa New Zealand (ATLAANZ) (pp. 68-88). Auckland, NZ: ATLAANZ.

Loviscek, A. and Cloutier, N. (1997) 'Supplemental Instruction and the enhancement of student performance in economics principles', The American Economist, 41(2), pp. 70-76. http://dx.doi.org/10.1177/056943459704100209

Lundeberg, M. A. and Moch, S. D. (1995) 'Influence of social interaction on cognition: connected learning in science', Journal of Higher Education, 66(3), pp. 312-335.

Martin, D. C. and Wilcox, F. K. (1996) Supplemental instruction: helping students to help each other, in Brown, S. and Wisker, G. (eds.) Enabling student learning: systems and strategies. London: Kogan Page and Staff and Educational Development Association (SEDA) pp. 97-101. 
McCarthy, A., Smuts, B. and Cosser, M. (1997) 'Assessing the effectiveness of supplemental instruction: a critique and a case study', Studies in Higher Education, 22(2), pp. 221-231. http://dx.doi.org/10.1080/03075079712331381054

Micari, M., Streitwieser, B. and Light, G. (2005) 'Undergraduates leading undergraduates: peer facilitation in a science workshop program', Innovative Higher Education, 30(4), pp. 269-288. http://dx.doi.org/10.1007/s10755-005-8348-y

Muldoon, R. (2008) 'Recognising and rewarding the contribution and personal development of peer supporters at university', Journal of Further and Higher Education, 32(3), pp. 207-219. http://dx.doi.org/10.1080/03098770802220405

Ogden, P., Thompson, D., Russell, A., and Simons, C. (2003) 'Supplemental instruction: short and long-term impacts', Journal of Developmental Education, 26(3), pp. 2-8.

Pugliese, T., Bolton, T., Jones, G., Roma, G., Cipkar, S. and Rabie, R. (2015) Evaluating the effects of the faculty of arts and social sciences mentor program. Toronto: The Higher Education Quality Council of Ontario. Available at: http://www.heqco.ca/enca/Research/ResPub/Pages/Evaluating-the-Effects-of-the-Faculty-of-Arts-andSocial-Sciences-Mentor-Program-.aspx (Accessed: 13 April 2016).

Rodger, S. and Tremblay, P. (2003) 'The effects of a peer mentoring program on academic success among first year university students', Canadian Journal of Higher Education, 33(3), pp. 1-17.

Shrestha, C., May, S., Edirisingha, P., Burke, L., and Linsey, T. (2008) 'From face-to-face to e-mentoring: does the "e" add any value for mentors?' International Journal of Teaching and Learning in Higher Education, 20(2), pp. 116-124.

Skalicky, J. (2008) 'Providing multiple opportunities for PASS leaders to reflect critically', Journal of Peer Learning, 1(1), pp. 91-98.

Skalicky, J. and Caney, A. (2010) 'PASS student leader and mentor roles: a tertiary leadership pathway', Journal of Peer Learning, 3(1), pp. 24-37. 
Smith, B. L. and MacGregor, J. T. (1992) 'What is collaborative learning?', in Goodsell, A. S., Maher, M. R., and Tinto, V. (eds.), Collaborative learning: a sourcebook for higher education. Pennsylvania: National Center on Postsecondary Teaching, Learning, and Assessment, pp. 10-30.

Smith, T. (2008) 'Integrating undergraduate peer mentors into liberal arts courses: a pilot study', Innovative Higher Education, 33(1), pp. 49-63. http://dx.doi.org/10.1007/s10755-007-9064-6

Stone, A., Meade, C. and Watling, R. (2012) 'Peer-assisted learning in research methods and statistics'. Psychology Teaching Review, 18(2), pp. 68-73

Stone, M. E., Jacobs, G. and Hayes, H. (2008) 'Supplemental instruction: student perspectives in the 21st century', in Lundell, D. B., Higbee, J.L., Duranczyk, I. M. and Goff, E. (eds.) Student standpoints about access programs in higher education. Minneapolis, MN: The Centre for Research on Developmental Education and Urban Literacy, University of Minnesota, pp. 129-141. Available at: http://files.eric.ed.gov/fulltext/ED499050.pdf (Accessed: 13 April 2016).

Stout, M. L. and McDaniel, A. J. (2006) 'Benefits to supplemental instruction leaders', in Stone, M. E. and Jacobs, G. (eds.) Supplemental Instruction: new visions for empowering student learning. San Francisco: Jossey-Bass, pp. 55-62.

Terrion, J. L. and Philion, R. (2008) 'The electronic journal as reflection- on- action: a qualitative analysis of communication and learning in a peer- mentoring program', Studies in Higher Education, 33(5), pp. 583-597. http://dx.doi.org/10.1080/03075070802373073

\section{Author details}

Melanie Giles is a Professor of Psychology and Head of School. She is also a Chartered Psychologist and a registered health practitioner with the HCPC. Her main research interests are in the area of health psychology and she is an active member of the 
Psychology Research Institute at Ulster. She also has a keen interest in learning and teaching. She has assumed a variety of administrative roles in this respect and is responsible for overseeing the quality of teaching and the development of enhancement activities. She is a trained PASS/SI Supervisor and is responsible for the introduction of the PASS peer mentoring scheme at Ulster. She is a Senior Fellow of the Higher Education Academy and a Fellow of the Centre for Higher Education Research Practice.

Amanda Zacharopoulou is a Senior Lecturer in the School of Law at Ulster University. She has been teaching for over twenty years and has an interest in legal education. She has occupied various teaching and learning roles within the university including that of Faculty Teaching and Learning Coordinator for Social Sciences. She is a trained PASS/SI Supervisor and has pioneered PASS (Peer Assisted Study Sessions) within the School of Law. She continues to develop student centred interventions within the School of Law designed to enhance the pre-entry, induction and transition experiences of law students. She is a Senior Fellow of the Higher Education Academy and a Fellow of the Centre for Higher Education Research Practice.

Dr Joan Condell is a Senior Lecturer in the School of Computing and Intelligent Systems in the Department of Computing and Engineering at Ulster University. She has been teaching maths and computing modules in Ulster since 1998. Joan has published work in computer imaging and maths, alongside robotics and health applications. This work includes publication in over 120 journal and conferences, successful completion of PhD students and the enhancement of student learning and engagement through peer assisted learning methods for maths (specifically PASS). She is a trained PASS/SI Supervisor. Her work has also extended in promoting computing as a career with initiatives such as wiCADET, a widening access project which involved teaching mobile app. development to local secondary pupils. 